\title{
KEANEKARAGAMAN JENIS IKAN DI SUNGAI BATANG GADIS MANDAILING NATAL SUMATERA UTARA
}

\author{
YUSNI ATIFAH, FITRI AguSTINA LUBIS
}

Program Studi Pendidikan Biologi, Universitas Muhammadiyah Tapanuli Selatan, Padangsidempuan

\section{A B S T R A C T}

Batang Gadis River, located in Mandailing Natal, faces a severe threat by the increase of human activities along the river. The fish community, as well as other biotas, is exposed to reducing environmental condition. Therefore, the study of fish community in this river is essential to get the most recent condition as a baseline data. The purpose of this research was to determine the species diversity of fish in Batang Gadis River of Mandailing Natal. This research used a descriptive exploratory method by surveying with purposive sampling method to collect samples at four specified stations. This study used a fishing net with a zig-zag pattern of sampling covered the river bank for about $200-300 \mathrm{~m}$ at each observation station. The collected fish samples were identified at the Biology Laboratory of the University of Muhammadiyah Tapanuli Selatan. This study found ten species of fish from five families. The family with the most significant members was Cyprinidae ( 6 species), and the other families, Bagridae, Clariidae, Nemachelidae, and Loricariidae, were found with only one species. The species diversity comprised of Rasbora lateristriata, Nemacheilus fasciatus, Mystacoleucus marginatus, Tor tambra, Cyprinus carpio, Clarias bathracus, Rasbora argyrotaenia, Barbonymus gonionotus, Puntius binotatus, Bagrus nemurus, and Pterygoplichthys pardalis. The fish population of Batang Gadis River has diversity index $\left(H^{\prime}\right)$ of 1.77 and similarity index $(\mathrm{E})$ of 0.77

KEY WORDS: fish, species diversity, Mandailing Natal, Batang Gadis River

\section{PENDAH U L UAN}

Sungai Batang Gadis merupakan sungai terpanjang dan terbesar di Mandailing Natal. Sungai ini mengalir hampir ke seluruh Kabupaten Mandailing Natal, mulai dari hulu di Ulu Pakantan Muara Sipongi, melewati beberapa kecamatan, hingga bermuara di Kecamatan Muara Batang Gadis. Aliran sungai ini melewati kawasan pemukiman, peternakan, persawahan, tambang pasir, taman wisata, dan bendungan. Pemanfaatan bendungan di Sungai Batang Gadis tersebut selain untuk menahan arus, mencegah banjir, dan tempat wisata, juga untuk keperluan irigasi.

Kegiatan masyarakat banyak dilakukan di sepanjang Sungai Batang Gadis seperti mandi, cuci, kakus, pembuangan sampah, dan penambangan emas. Kegiatan tersebut menghasilkan limbah yang terbuang ke Sungai Batang Gadis yang di antaranya dapat berupa bahan-bahan beracun seperti detergen, shampoo, dan bahan pemutih pakaian (kaporit).

Kegiatan penambangan emas di Sungai Batang Gadis diketahui langsung membuang limbahnya ke sungai yaitu berupa minyak dan sedimen hasil pengorekan tanah yang menyebabkan kualitas air di sungai tersebut menurun (Anas, 2010). Kualitas air yang menurun dapat mempengaruhi kehidupan biota di sungai tersebut, termasuk ikan, sehingga kondisi terkini diversitas jenis ikan di sungai tersebut sangat menarik untuk diteliti.

Penelitian ini bertujuan untuk mengetahui keanekaragaman, kelimpahan, dan distribusi jenis ikan di Sungai Batang Gadis Mandailing Natal. Hasil penelitian ini diharapkan dapat digunakan sebagai data dasar dan pertimbangan untuk menunjang pelestarian jenis ikan di Sungai Batang Gadis, dan sebagai masukan dalam pembuatan kebijakan pengelolaan kawasan, karena masih terbatasnya informasi mengenai jenis ikan yang terdapat di Sungai Batang Gadis.

\section{ME T O D E}

Penelitian ini dilaksanakan pada bulan Juni sampai Agustus 2017 di sepanjang aliran Sungai Batang Gadis Mandailing Natal. Metode yang digunakan dalam penentuan stasiun untuk pengambilan sampel ikan adalah Purposive Random Sampling yaitu berdasarkan pertimbangan terwakilinya gambaran keadaan perairan sungai, terutama berkaitan dengan kegiatan masyarakat dan penangkapan ikan di sungai tersebut. Adapun deskripsi empat stasiun pengambilan sampel adalah sebagai berikut: Stasiun I merupakan hulu dari Sungai Batang Gadis, berada di desa Simpang Banyak Julu, kecamatan Ulu Pungkut, kabupaten Mandailing Natal, dan secara geografis berada pada 0³0'991"LU, 9947'168"BT; Stasiun II berada di desa Tamiang, kecamatan Kotanopan, kabupaten Mandailing Natal, dan secara geografis berada pada $0^{\circ} 39^{\prime} 026^{\prime \prime} \mathrm{LU}$, $99^{\circ} 41^{\prime} 546^{\prime \prime}$ BT. Pada daerah ini terdapat aktivitas masyarakat seperti mandi,cuci dan kakus (MCK); Stasiun III berada di desa Tambang Bustak, kecamatan Kotanopan, kabupaten Mandailing Natal dan secara geografis berada pada $0^{\circ} 39^{\prime} 374^{\prime \prime} \mathrm{LU}, 99^{\circ} 43^{\prime} 068^{\prime \prime} \mathrm{BT}$. Pada daerah ini dijumpai berbagai aktivitas masyarakat seperti mandi, cuci, kakus, dan aktivitas penambangan; Stasiun IV merupakan hilir Sungai Batang Gadis, berada di desa Dalan Lidang Panyabungan, kabupaten Mandailing Natal dan secara geografis berada pada $0^{\circ} 48^{\prime} 352^{\prime \prime} \mathrm{LU}, 99^{\circ} 34^{\prime} 272^{\prime \prime} \mathrm{BT}$.

Pengambilan ikan menggunakan jaring harpa dengan penyusuran tepi sungai secara zig-zag sepanjang 200-300 m pada setiap stasiun pengamatan. Pengambilan ikan dilakukan sebanyak tiga kali ulangan dengan selang waktu satu minggu. Ikan yang tertangkap disortir sementara, menurut perkiraan pengelompokan karakter yang sama, minimal hingga taraf familia atau, jika memungkinkan, spesies, dan dihitung jumlah individu tiap jenisnya. Spesimen ikan diawetkan dalam larutan formalin $10 \%$ dan diberi label berisi keterangan yang diperlukan berupa lokasi atau koordinat, tanggal pengoleksian, kolektor, metode penangkapan dan alat tangkap. Seluruh spesimen 
selanjutnya dimasukkan ke dalam kantong plastik. Setiap kantong plastik berisi spesimen-spesimen dari satu lokasi dan diberi label lokasi. Spesimen ikan tersebut dimasukkan ke dalam kontainer yang kuat. Kualitas air diukur secara insitu, mencakup temperatur, $\mathrm{pH}$, kecerahan, kedalaman, dan kecepatan arus. Sampel DO, BOD dibawa ke laboratorium untuk dianalisis, dengan pengawetan menggunakan es pada temperatur sekitar $4^{\circ} \mathrm{C}$ menjelang pengamatan di laboratorium.

Spesimen dari lapangan kemudian dibawa ke laboratorium, lalu dicuci dengan air mengalir, dan selanjutnya disimpan dalam larutan alkohol $70 \%$. Identifikasi ikan dilakukan di Laboratorium Biologi Universitas Muhammadiyah Tapanuli Selatan dengan mengacu kepada Kottelat et al. (1993), Weber and de Beaufort (1913) dan Roberts (1989).

Nilai indeks keanekaragaman (Shannon-Wiener diversity index) dan nilai indeks kemerataan (evennes) menurut Krebs (1989) dihitung berdasarkan data yang diperoleh, dan hasilnya dianalisis secara deskriptif dengan mengacu pada batasan nilai dari Krebs (1989) dan Magurran (1988).

\section{HASIL DAN PEMBAHASAN}

Individu ikan yang berhasil dikumpulkan selama penelitian ini berjumlah 866 ekor yang dapat dikategorikan ke dalam 10 spesies dan 5 familia (Tabel 1). Familia yang paling banyak ditemukan adalah Cyprinidae yang terdiri atas 6 spesies, sedangkan familia lainnya, Nemachelidae, Bagridae, Clariidae dan Loricarinae, masing-masing ditemukan 1 spesies (Gambar 1 ).

Hasil penelitian memberikan informasi bahwa 10 spesies ikan yang ditemukan tersebar mulai dari hulu hingga hilir Sungai Batang Gadis. Spesies ikan tersebut merupakan ikan konsumsi masyarakat Mandailing Natal, kecuali ikan Sapu-sapu (Gambar 2). Spesies yang paling banyak ditemukan sesuai dengan pendapat Bhat (2003) dan Jutagate et al. (2001) yaitu pada umumnya spesies ikan yang hidup di perairan sekitar daratan Asia Tenggara didominasi oleh ikanikan dari familia Cyprinidae.
Tabel 1. Spesies ikan yang ditemukan di Sungai Batang Gadis Mandailing Natal

\begin{tabular}{cll}
\hline No. Nama Lokal & Familia & Nama Ilmiah \\
\hline 1 Ikan Garing & Cyprinidae & Tor tambra \\
2 Ikan Cencen & & Mystacoleucus marginatu \\
3 Ikan Mas & & Cyprinus carpio \\
4 Ikan Keperas & & Puntius binotatus \\
5 Ikan Seluang & & Rasbora argyrotaenia \\
6 Ikan Tawes & & Barbonymus gonionotus \\
7 Ikan Baung & Bagridae & Bagrus nemurus \\
8 Ikan Lele & Clariidae & Clarias batrachus \\
0 Ikan Sapu-sapu & Loricariidae & Pterygoplichthys pardalis \\
10 Ikan Incor/UcengNemacheilidcNemacheilus fasciatus \\
\hline
\end{tabular}

Adapun familia yang sedikit jumlah anggotanya meliputi familia Bagridae, Clariidae, Nemachelidae dan Loricarinae masing-masing familia diwakili oleh satu jenis (Gambar 2). Hasil penelitian di beberapa sungai di kawasan pulau Sumatera menunjukkan bahwa familia Cyprinidae terlihat lebih mendominasi jika dibandingkan dengan familia ikan air tawar lainnya. Siregar (1993) menyatakan bahwa familia Cyprinidae merupakan familia ikan air tawar yang paling utama menempati beberapa sungai di pulau Sumatera.

Tabel 2. Indeks keanekaragaman dan indeks kemerataan jenis ikan di Sungai Batang Gadis Mandailing Natal

\begin{tabular}{lcc}
\hline Stasiun & $\begin{array}{c}\text { Indeks } \\
\text { Keanekaragaman } \\
(\boldsymbol{H})\end{array}$ & $\begin{array}{c}\text { Indeks } \\
\text { Kemerataan } \\
\text { (E) }\end{array}$ \\
\hline Stasiun 1 & 1,12 & 0,80 \\
Stasiun 2 & 1,41 & 0,78 \\
Stasiun 3 & 1,44 & 0,89 \\
Stasiun 4 & 1,70 & 0,87 \\
Seluruh Stasiun & 1,77 & 0,77 \\
\hline
\end{tabular}

Indeks keanekaragaman menunjukkan bahwa keanekaragaman jenis ikan di Sungai Batang Gadis Mandailing Natal Sumatera Utara termasuk dalam kondisi sedang yaitu 1,77 (Tabel 2).

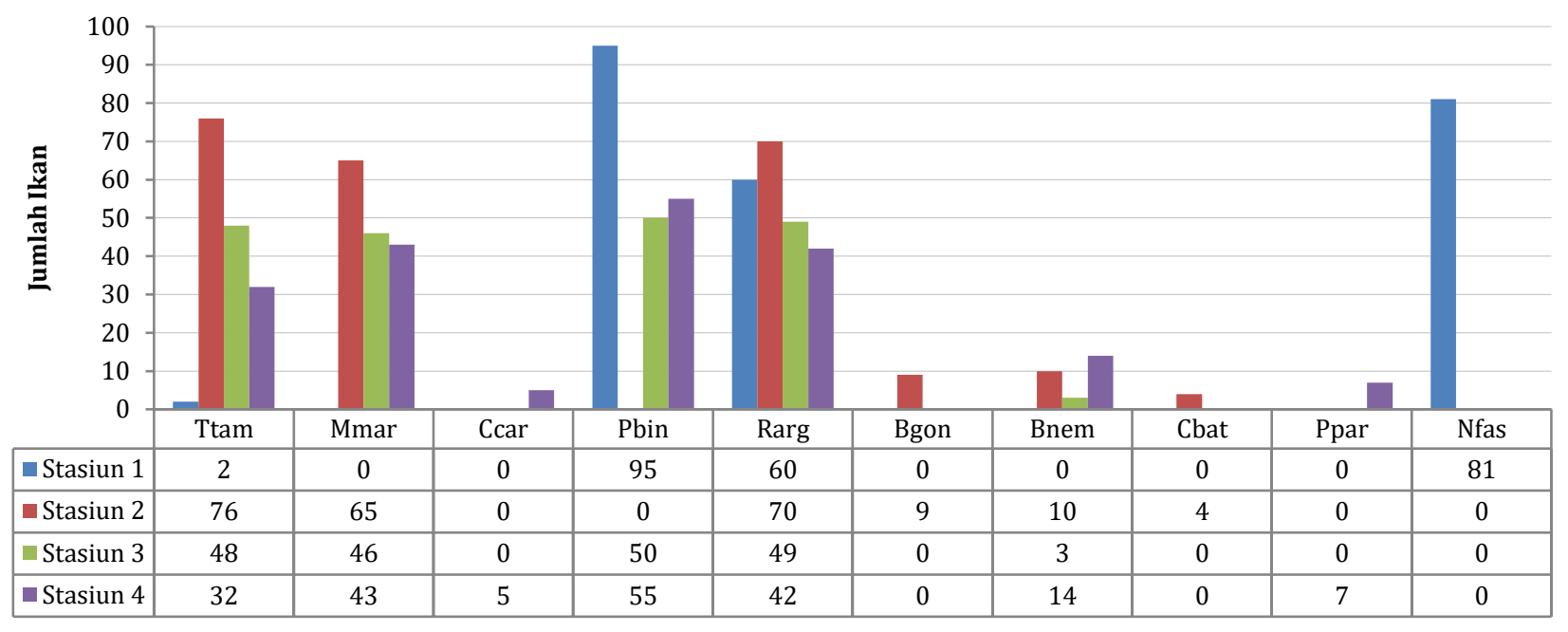

Jenis Ikan

Gambar 1. Distribusi spasial ikan di Sungai Batang Gadis Mandailing Natal. Ttor $=$ Tor tambra , Mmar $=$ Mystacoleucus marginatus, Ccar $=$ Cyprinus carpio, Ppun $=$ Puntius binotatus, Rarg $=$ Rasbora argyrotaenia, Bgon $=$ Barbonymus gonionotus, Bnem $=$ Bagrus nemurus, Cbat $=$ Clarias batrachus, Ppar $=$ Pterygoplichthys pardalis, Nfas $=$ Nemacheilus fasciatus 

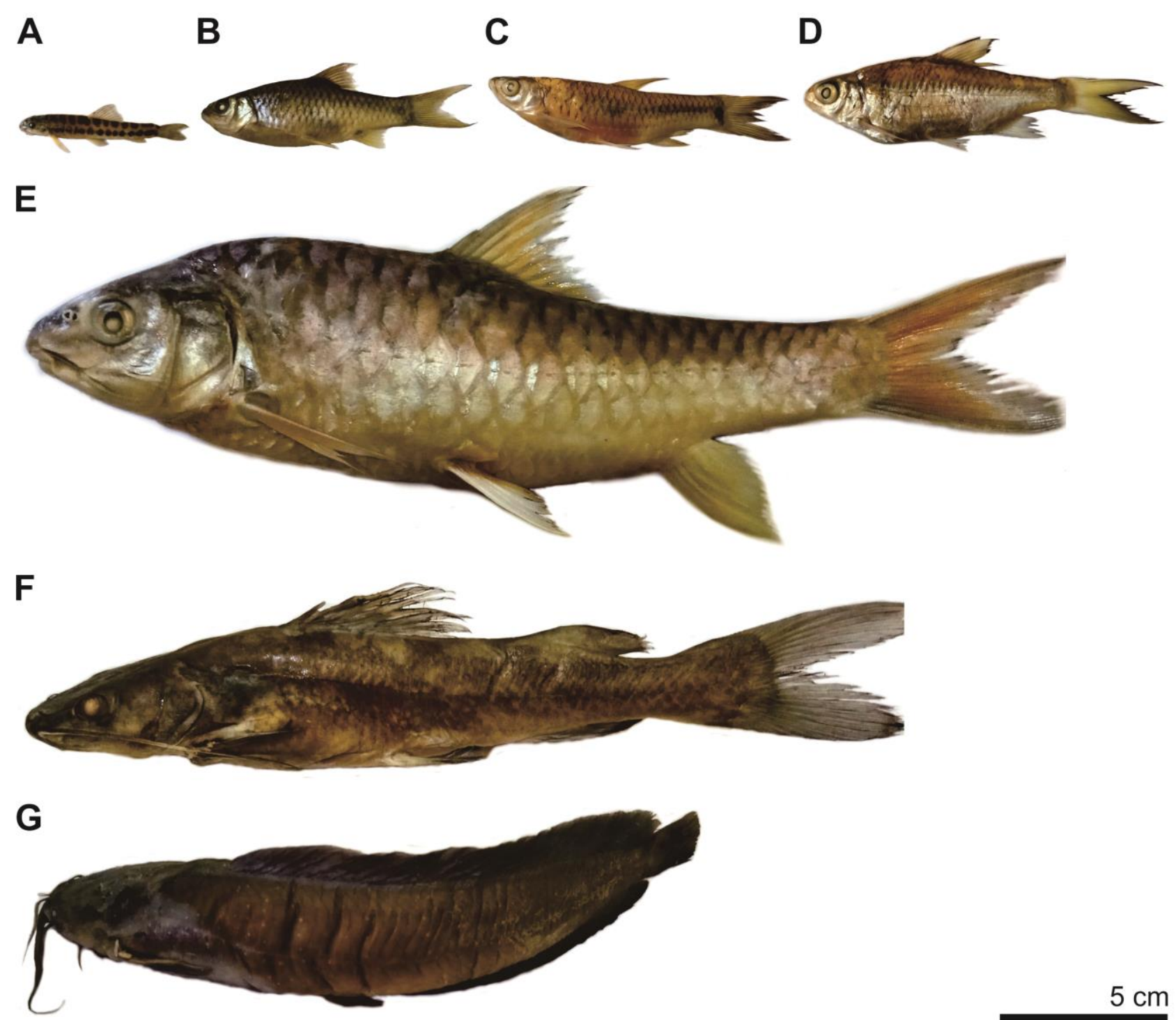

Gambar 2. Beberapa jenis ikan yang ditemukan di Sungai Batang Gadis Mandailing Natal.

A. Nemacheilus fasciatus, B. Puntius binotatus, C. Rasbora argyrotaenia, D. Mystacoleucus marginatus, E. Tor tambra, F. Bagrus nemurus, G. Clarias bathracus

Menurut Magurran (1988) keanekaragaman tinggi apabila nilai indeks keanekaragaman $H^{\prime}>3$; sedang jika $1<H^{\prime}<3$ dan rendah jika $H^{\prime}<1$. Semakin tinggi $H^{\prime}$ mengindikasikan semakin banyak jumlah jenis dan kelimpahan relatifnya. Nilai $H^{\prime}$ tertinggi ditunjukkan pada Stasiun IV (Dalan Lidang) yang mempunyai jumlah jenis paling tinggi ( 7 jenis) sehingga nilai indeks keanekaragaman $H^{\prime}$ sebesar 1,70 atau $H^{\prime}<3$.

Indeks kemerataan jenis menunjukkan bahwa penyebaran individu suatu jenis secara keseluruhan di Sungai Batang Gadis Mandailing Natal Sumatera Utara termasuk merata dengan nilai 0,77 . Krebs (1989) menetapkan kriteria kisaran nilai indeks kemerataan, yaitu kemerataan jenis tinggi apabila indeks kemerataan $\mathrm{E}>0,6$; sedang jika $0,4<\mathrm{E}<0,6$ dan rendah jika $\mathrm{E}<0,4$. Ikan memiliki kemelimpahan yang beragam pada waktu dan lokasi yang berbeda. Jenis ikan yang memiliki kemelimpahan dan juga dominansi tertinggi pada pengamatan pada empat stasiun di Sungai Batang Gadis adalah T. tambra, $R$. argyrotaenia, $M$. marginatus, $P$. binotatus dan $B$. nemurus. Jenis-jenis tersebut memiliki kelimpahan tertinggi karena memiliki kemampuan dalam beradaptasi dan dapat memanfaatkan potensi sumber daya yang ada untuk mencukupi hidup. Indeks keanekaragaman ikan yang tinggi pada sungai berhubungan dengan luas dan kedalaman sungai. Adanya hubungan positif antara kekayaan jenis dengan suatu area yang ditempati berhubungan pula dengan keanekaragaman jenis ikan. Hasil pengamatan jenis ikan yang ditangkap pada stasiun yang berbeda menunjukkan jenis ikan yang tertangkap berbeda juga.

Pada Gambar 1, keberadaan jenis ikan yang berbeda pada setiap stasiun dipengaruhi oleh faktor fisika dan kimia air sungai tersebut. Ikan yang ditemukan pada Stasiun I ada empat jenis yaitu, $P$. binotatus, N. fasciatus, M. marginatus dan T. tambra. Jenis ikan $N$. fasciatus hanya ditemukan di Stasiun I. $N$. fasciatus merupakan jenis ikan yang hidup di sungai yang banyak batu-batuannya. Kondisi sungai pada Stasiun I ditemukan banyak batuan yang 
memungkinkan ikan N. fasciatus untuk hidup dan berkembang. Perbedaan sebaran spesies secara spasial menunjukkan bahwa masing-masing lokasi penelitian menyediakan relung (habitat dan makanan) yang berbeda sehingga komposisi spesiesnya berbeda. Sesuai dengan pendapat (Li et al., 2012) bahwa sebaran kekayaan spesies secara spasial terkait dengan variabilitas habitat dan keberadaan mikrohabitat, komposisi substrat dan kedalaman perairan (Pusey et al., 1993).

Ikan yang ditemukan pada Stasiun II ada enam jenis yaitu, M. marginatus, T. tambra, B. nemurus, $C$. bathracus, $R$. argyrotaenia dan $B$. gonionotus. Jenis $T$. tambra ditemukan dengan jumlah yang paling banyak di antara jenis ikan lainnya. Ikan yang ditemukan pada Stasiun III ada lima jenis yaitu, M. marginatus, T. tambra, B. nemurus, $R$. argyrotaenia dan $P$. binotatus. Jenis T. tambra ditemukan dengan jumlah yang paling banyak diantara jenis ikan lainnya. Tujuh jenis ikan pada Stasiun IV yaitu, M. marginatus, T. tambra, B. nemurus, $R$. argyrotaenia, $P$. binotatus, $C$. carpio dan $P$. pardalis. Jenis $P$. binotatus ditemukan dengan jumlah yang paling banyak di antara jenis ikan lainnya. Pada Stasiun Ini juga ditemukan dua jenis ikan yang tidak ditemukan pada stasiun lain yaitu ikan mas (C. carpio) dan ikan Sapu-sapu (P. pardalis).

Ikan paling banyak diperoleh pada Stasiun I, kemudian menyusul Stasiun II, III dan IV (Gambar 3). Pada Stasiun I diperoleh 238 ekor ikan dari empat spesies yaitu P. binotatus, T. tambra, R. argyrotaenia dan N. fasciatus. Pada Stasiun II diperoleh 236 ekor ikan dari enam spesies yaitu B. gonionatus, T. tambra, $R$. argyrotenia, $M$. marginatus, $B$. nemurus, dan $C$. batrachus. Pada Stasiun III diperoleh 196 ekor ikan dari lima spesies yaitu T. tambra, R. argyrotaenia, $M$. marginatus, $B$. nemurus, dan $P$. binotatus. Pada Stasiun IV diperoleh 191 ekor ikan dari tujuh spesies yaitu $C$. carpio, T. tambra, $R$. latestriata, M. marginatus, $B$. nemurus, $P$. binotatus dan $P$. pardalis.

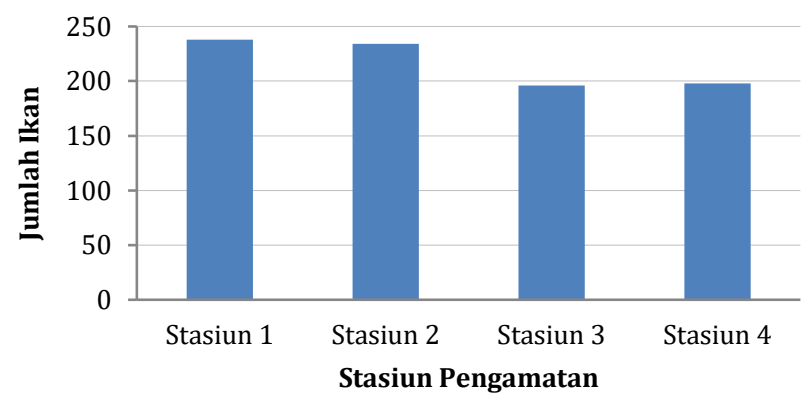

Gambar 3. Jumlah ikan pada setiap stasiun di Sungai Batang Gadis Mandailing Natal

Sungai Batang Gadis menunjukkan nilai keanekaragaman jenis ikan yang sedang mulai dari hulu hingga ke hilir sungai. Keanekaragaman dan kelimpahan ikan juga ditentukan oleh karakteristik habitat perairan. Kecepatan arus sungai ditentukan perbedaan kemiringan sungai dan keberadaan tumbuhan di sepanjang daerah aliran sungai yang berasosiasi dengan keberadaan satwa penghuninya (Ross, 1997).

Menurut Ardani dan Organsastra (2009) kemerataan ikan berkisar 0-1. Kriteria nilai kemerataan mendekati 0 maka penyebaran individu antar jenis relatif tidak sama dan ada sekelompok individu jenis tertentu yang melimpah. Sebaliknya bila nilai kemerataan mendekati 1 maka penyebaran individu antar jenis relatif sama. Nilai kemerataan jenis ikan pada Stasiun III (Tamiang) tinggi apabila dibandingkan dengan stasiun lainnya.

Hasil pengambilan ikan terbanyak pada Stasiun I yaitu di Desa Simpang Banyak, yang merupakan Hulu dari Sungai Batang Gadis. Salah satu faktor yang mempengaruhi keberadaan ikan di suatu perairan adalah faktor fisika kimia air tersebut (Tabel 3). Hasil pengukuran faktor fisika kimia air pada Stasiun I menunjukkan kondisi perairan yang masih bersih dari bahan tercemar dan memiliki DO yang lebih tinggi dari stasiun pengamatan lainnya. DO yang tinggi memungkinkan banyak biota air dapat hidup pada perairan tersebut. Namun, ikan Garing (T. tambra) sangat sedikit ditemukan pada Stasiun I dibanding dengan stasiun yang lain. Hal ini dikarenakan temperatur pada stasiun 1 yang rendah.

Tabel 3. Parameter fisika kimia air Sungai Batang Gadis Mandailing Natal

\begin{tabular}{lcccccr}
\hline Parameter & \multirow{2}{*}{ Satuan } & \multicolumn{5}{c}{ Stasiun } \\
\cline { 3 - 7 } Fisika-Kimia & & I & II & III & IV & \\
\hline Temperatur & ${ }^{\circ} \mathrm{C}$ & 18 & 25 & 27 & 27 & 24,25 \\
$\mathrm{pH}$ & - & 6,2 & 5,7 & 4,5 & 4,5 & 5,22 \\
DO & $\mathrm{mg} / \mathrm{l}$ & 6,2 & 5,1 & 5,5 & 5,2 & 5,50 \\
BOD & $\mathrm{Mg} / \mathrm{l}$ & 2,0 & 2,7 & 3,4 & 3,0 & 2,77 \\
Kedalaman & $\mathrm{Cm}$ & $30-50$ & $50-80$ & $80-100$ & $80-200$ & - \\
Arus & m/detik & 0,1 & 0,07 & 0,09 & 0,05 & - \\
Kekeruhan & NTU & 10,2 & 15,2 & 34,2 & 28,5 & 22,02 \\
\hline
\end{tabular}

Berdasarkan hasil penelitian diperoleh temperatur dari masing-masing stasiun di perairan Sungai Batang Gadis berkisar antara $18-27^{\circ} \mathrm{C}$ dengan temperatur rata-rata $24,25^{\circ} \mathrm{C}$. Kisaran temperatur terendah pada Stasiun I sekitar $18^{\circ} \mathrm{C}$ dan temperatur tertinggi berada pada Stasiun III dan IV sebesar $27^{\circ} \mathrm{C}$ karena letak daerah yang rendah dan merupakan pusat atau kabupaten kota Mandailing Natal. Menurut Effendi (2003) kisaran temperatur optimal bagi kehidupan organisme di perairan tropis adalah $20-30^{\circ} \mathrm{C}$. Hasil pengukuran parameter fisika-kimia air Sungai Batang Gadis ini menunjukkan hasil yang menurun pada beberapa aspek. Hasil pengukuran yang dilakukan oleh Hidayati et al. (2015) menunjukkan nilai DO 6,2 $\mathrm{mg} / \mathrm{l}$, BOD 3,07 $\mathrm{mg} / \mathrm{l}$, kekeruhan 32,3 NTU, temperatur $23,5^{\circ} \mathrm{C}$ dan $\mathrm{pH} 7,05$. $\mathrm{pH}$ air menurun dari 7,05 menjadi 5,22 yang berarti kondisi perairan menjadi asam. DO air juga turun dari $6,2 \mathrm{mg} / \mathrm{l}$ menjadi 5,50 mg/l yang menunjukkan bahwa kandungan oksigen perairan juga menurun namun masih dalam kondisi yang baik untuk mendukung kehidupan biota air di Sungai Batang Gadis. Hal ini sesuai dengan Salmin (2005) bahwa suatu perairan dapat dikatakan baik dan mempunyai tingkat pencemaran yang rendah 
jika kadar oksigen terlarutnya (DO) lebih besar dari 5 mg/l. Tetapi, apabila DO berada di bawah $4 \mathrm{mg} / \mathrm{l}$, maka hal ini merupakan suatu tanda bahwa kondisi air cukup membahayakan bagi biota pengguna oksigen.

\section{K E S I M P U L A N}

Ikan yang berhasil dikumpulkan selama penelitian berjumlah 866 ekor yang dikategorikan ke dalam 5 familia dan 10 spesies ikan. Spesies ikan yang ditemukan adalah Tor tambra, Puntius binotatus, Rasbora argyrotaenia, Nemacheilus fasciatus, Barbonymus gonionatus, Mystacoleucus marginatus, Bagrus nemurus, Clarias batrachus, Cyprinus carpio dan Pterygoplichthys pardalis. Indeks keanekaragaman jenis ikan di Sungai Batang Gadis tergolong sedang dengan nilai 1,77 dan indeks kemerataan jenis ikan di Sungai Batang Gadis tergolong tinggi dengan nilai 0,77.

\section{UCAPAN TERIMA KASIH}

Penelitian ini didanai oleh Direktorat Riset dan Pengabdian Masyarakat Direktorat Jenderal Penguatan Riset dan Pengembangan Kementerian Riset, Teknologi, dan Pendidikan Tinggi berdasarkan Surat Keputusan Ketua LPPM Universitas Muhammadiyah Tapanuli Selatan Nomor: 031/K1.1/LT.1/2017 tahun 2017. Penelitian ini terlaksana dengan bantuan berbagai pihak, untuk itu penulis mengucapkan terimakasih kepada Faisal, Nurdin, Somad, Ibu Melva, Ibu Fatma, Ibu Nurmaini, Bapak Abu, dan Bapak Ariaji.

\section{DAFT AR REFERENSI}

Anas. 2010. Analisis kandungan merkuri pada air sungai dan ikan akibat tambang emas tradisional serta tata cara penggunaan merkuri oleh penambang emas di desa Hutapungkut kecamatan Kotanopan kabupaten Mandailing Natal [skripsi]. Universitas Sumatera Utara-Medan.
Ardani B, Organsastra. 2009. Struktur komunitas ikan di danau Bagamat Petuk Bukit. Journal of Tropical Fisheries. 4(1):356367

Bhat, A. 2003. Diversity and composition of freshwater fishes in river systems of Central Western Ghats, India. Enviromental Biology of Fishes. 68: 25-38.

Effendi H. 2003. Telaah kualitas air bagi pengelolaan sumberdaya dan lingkungan perairan. Yogyakarta: Kanisius.

Hidayati N, Djayus Y, Riri E. 2015. Efek aktifitas masyarakat terhadap kelimpahan ikan Garing (Tor tambra) di sungai Batang Gadis kabupaten Mandailing Natal Sumatera Utara. Aquacoastmarine. 7(2): 12.

Jutagate T, Lamkom T, Satapornwanit K, Naiwinit W, Petchuay C. 2001. Fish species diversity and ichthyomass in Pak Mun reservoir, five years after impoundment. Asian Fisheries Science. 14:417-424.

Kottelat M, Whitten AJ, Kartikasari SN, Wirjoatmojo S. 1993. Freshwater fishes of Western Indonesia and Sulawesi. Singapore: Periplus Editions.

Krebs CJ. 1989. Ecological methodology. New York: Harper \& Row.

Li J, Huang L, Zou L, Kano Y, Sato T, Yahara T. 2012. Spatial and temporal variation of fish assemblages and their associations to habitat variables in a mountain stream of north Tiaoxi River, China. Environ Biol Fish. 93: 403-417.

Magurran AE. 1988. Ecological diversity and its measurement. New Jersey: Priceton UniversityPress.

Pusey BJ, Arthington AH, Read MG. 1993. Spatial and temporal variation in fish assemblage structure in the Mary River, southeastern Queensland: the influence of habitat structure. Environ Biol Fish. 37:355.

Roberts TR. 1989. The freshwater fishes of western Borneo (Kalimantan Barat, Indonesia). San Fransisco: California Academy of Science.

Ross MR. 1997. Fisheries conservation and management. New York: Prentice Hall.

Salmin. 2005. Oksigen terlarut (DO) dan kebutuhan oksigen biologi (BOD) sebagai salah satu indikator untuk menentukan kualitas perairan. Oseana. 30(3): 21-26.

Siregar S, Putra RM, Sukendi. 1993. Fauna ikan di perairan sektor Bukit Tigapuluh Siberida, Sumatera. Rain Forest and Resource Management. Proceeding of the Norinda; 1993 May 23-25; Jakarta.

Weber M, de Beaufort LF. 1913. The fishes of the Indo-Australian archipelago II-Malacopterygii, Myctophoidea, Ostariophysi: I, Siluroidea. Leiden: E.J. Brill Ltd. 